\title{
Strength exercise for balance and gait in HIV-associated distal symmetrical polyneuropathy: A randomised controlled trial
}

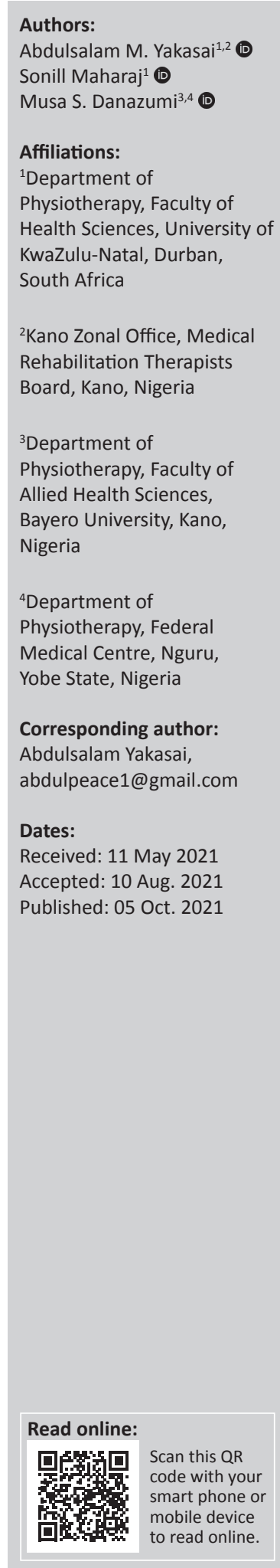

Background: HIV-associated peripheral neuropathy $(\mathrm{PN})$ is a common neurological complication associated with HIV infection. Distal symmetrical polyneuropathy (DSPN) is the most commonly occurring type, which is associated with symptoms such as numbness, unsteady gait and, in some cases, muscle atrophy and weakness when myelinated nerve fibres are affected. If unmyelinated nerve fibres are affected, a painful neuropathy and autonomic symptoms may occur.

Objectives: This research study assessed the effects of a strength exercise intervention on balance impairment and gait disturbance amongst individuals living with HIV-associated DSPN.

Method: The study was a single-blinded, randomised controlled trial (RCT) with participants sourced from four HIV centres in Kano metropolis, Nigeria. The intervention was supervised and included progressive resistance exercise (PRE) (three 40-min sessions per week for 12 weeks) using a quadriceps bench $(n=44)$. The control group (CG) included the non-exercise group $(n=47)$. The two groups continued to receive routine care. Data were summarised and analysed using inferential statistics (SPSS version 20 program) with the alpha level set at $<0.05$.

Results: At 12 weeks, the results revealed significant improvement with regard to balance performance $(p=0.001)$ and walking ability $(p=0.001)$ in the training group. In contrast, no significant differences in balance $(P=0.677)$ or gait $(P=0.578)$ were observed in the CG.

Conclusion: The findings suggest that PRE is beneficial for balance impairment and gait disturbance caused by neuropathy in persons living with HIV and receiving antiretroviral drugs.

Keywords: HIV-associated neuropathy; balance; gait; strength training; outcomes; rehabilitation; antiretroviral therapy.

\section{Introduction}

Peripheral neuropathy (PN) is a neurological condition affecting the sensory, motor or autonomic peripheral nerves. The classification of PN is generally based on the cause or pathological features of the nerve fibres affected. It can be subdivided based on primary myelin or axonal damage into demyelinating or axonal PN. ${ }^{1}$ The global estimate of HIV-associated neuropathy varies widely from $1.73 \%$ to $69.4 \%$ in different HIV-infected populations. ${ }^{2}$ Sadly, PN was not only shown to be associated with HIV infection itself but in many cases also triggered by treatment with antiretroviral agents. ${ }^{3}$ Growing evidence of unwanted adverse effects of the early antiretrovirals (ARVs) led to the use of safer, later generation ART in many countries. Peripheral neuropathy nontheless still remains important as the most common neurological disorder of people living with HIV (PLHIV). ${ }^{4}$

A number of studies from resource-constrained settings including sub-Saharan Africa report that the risk of HIV-associated neuropathy amongst patients on ART to be high (between $30 \%$ and $64 \%){ }^{5,6}$ Indeed, HIV-associated distal symmetrical polyneuropathy (DSPN) is reportedly the most common neurological complication of HIV infection. ${ }^{7}$ Individuals living with DSPN experience pain, numbness, fatigue and muscle weakness. ${ }^{8,9}$ These symptoms may become debilitating with locomotor instability resulting in an altered gait, an increased rate and incidence of falls, and decreased quality of life (QOL). ${ }^{10}$ The falls are attributed to the balance and gait abnormalities. ${ }^{11}$

How to cite this article: Yakasai AM, Maharaj S, Danazumi MS. Strength exercise for balance and gait in HIV-associated distal symmetrical polyneuropathy: A randomised controlled trial. S Afr J HIV Med. 2021;22(1), a1268. https://doi.org/10.4102/sajhivmed.v22i1.1268

Copyright: (C) 2021. The Authors. Licensee: AOSIS. This work is licensed under the Creative Commons Attribution License. 
Gait requires balance, power and coordination of larger groups of muscles of the lower extremities to permit the body to be propelled forward in a rhythmic motion. This function is diminished or lost in persons with neuropathy. ${ }^{12}$

Walking is a complex task that requires the coordinated function of the musculoskeletal, neuromuscular and cardiopulmonary systems. As DSPN progresses, symptoms such as 'numbness', pins and needles and 'pain' in the soles of the feet worsen the disturbed gait. ${ }^{13}$ Functional limitations, psychological distress and the loss of independence further compound the disability of those with HIV-associated DSNP. ${ }^{14,15}$ These negative effects and the risk of injury impact the survival of affected individuals. ${ }^{12,13}$

Exercise is generally regarded as safe for HIV-infected persons because it does not compromise immune function, boosts functional capacity, strength, physical fitness, mood, wellbeing, and may ameliorate muscle wasting and lipodystrophy. ${ }^{16,17}$ Previous studies have investigated the effect of aerobic and resistance exercise individually or in combination on immune function, psychological factors, cardiorespiratory fitness, strength, body composition, $\mathrm{QOL}^{17,18}$ and the ART-induced metabolic complications of PLHIV. ${ }^{19}$ The findings from these studies reveal that moderate- to highintensity aerobic exercise is safe and elicits favourable and beneficial changes in all the variables examined.

Physical therapy interventions have been shown to help address balance impairment, gait disturbance and to have a positive effect on the QOL of persons with complex chronic illnesses. ${ }^{20}$ In clinical practice, the physical therapists will use therapeutic resistance exercises that cause muscular contraction, microscopic damage/tearing of muscle, and repair that permits the restoration/increase of muscle power, tone, mass and endurance. ${ }^{21} \mathrm{~A}$ marked improvement in postural sway, joint flexibility, pain reduction, balancestance, gait speed and QOL has been observed following 'exergaming exercise' and strength training by PLHIV who have postural and walking impairment. ${ }^{17,22,23} \mathrm{~A}$ recent study further suggests that regular strength exercise may reduce HIV-neuropathic pain. ${ }^{24}$

Studies of the role of exercise in the rehabilitation of those on ART and living with neuropathy are scarce. ${ }^{24}$ To the best of the authors' knowledge, there is no data on the impact of progressive resistance exercise (PRE) in the management of balance impairment and gait disturbance in HIV-positive individuals who develop DSPN. This study investigated the effect of PRE on balance impairment and the walking ability of HIV-positive individuals on ART and living with neuropathy.

\section{Methods}

\section{Research design}

This was a single-blinded, pre-test, post-test randomised controlled trial (RCT).

\section{Participants}

Participants were patients living with HIV and attending local HIV centres. A neurologist performed a baseline physical assessment to confirm the presence of DSPN before enrolling the subjects in the study. The criteria for inclusion were: individuals aged 20-55 years, diagnosed with DSPN on ART from the ART clinics, able to ambulate unsupported and able to complete the 6-min walk test. The exclusion criteria were non-HIV related DSPN, serious cardiac pathology, musculoskeletal system pathology, loss of protective sensation of the feet, difficulty to walk without support, cerebrovascular accident and the following medical conditions such as diabetes mellites, high blood pressure (stage 2), hypoactive thyroid, vitamin B12 and folate deficiencies, co-infection with syphilis and chronic hepatitis $\mathrm{C}$, the use of drugs known to cause PN, substance or alcohol abuse and kidney failure.

\section{Population, site and sampling}

The RCT included 102 participants on ART diagnosed with HIV-associated DSPN who attended four ART clinics situated in Murtala Mohammed Specialist Hospital (MMSH), Mohammed Abdullahi Wase Specialist Hospital (MAWSH), Infectious Diseases Hospital, and international clinics and hospitals using the purposive sampling technique. The choice of purposive sampling was to include HIV-infected individuals from various settings around Kano metropolis, with different languages and socioeconomic backgrounds.

\section{Sample size estimation}

The parameters to calculate sample size were set as follows: power of the study $=80 \%$, alpha level $<0.05$, groups $=2$, effect size $f=0.32$ (medium) and number of repeated measures $=3$. A sample of 43 participants would be required in each group. The sample size of 86 was sufficient for this study; however the number of participants recruited was increased to 166 to accommodate the expected attrition. The participants were divided into two groups: PRE group and a control group (CG). An independent physiotherapist conducted randomisation using a computer random number allocation sequence. Based on the initial assessment, 55 participants were disqualified during the initial examination because of the absence of signs or symptoms of neuropathy and nine participants failed the stress tests, leaving 102 participants for randomisation into exercise and CGs. Ninety-one participants completed the study as shown in the consort flowchart of the study (Figure 1).

\section{Assessment and diagnosis Subjective peripheral neuropathy scale}

The Subjective Peripheral Neuropathy Scale (SPNS) was used to assess the presence of DSPN. Participants were asked to tick the box in front of the option that applied to them. The options were as follows: 'always been normal' to indicate the presence of the symptoms before but not present during the previous 


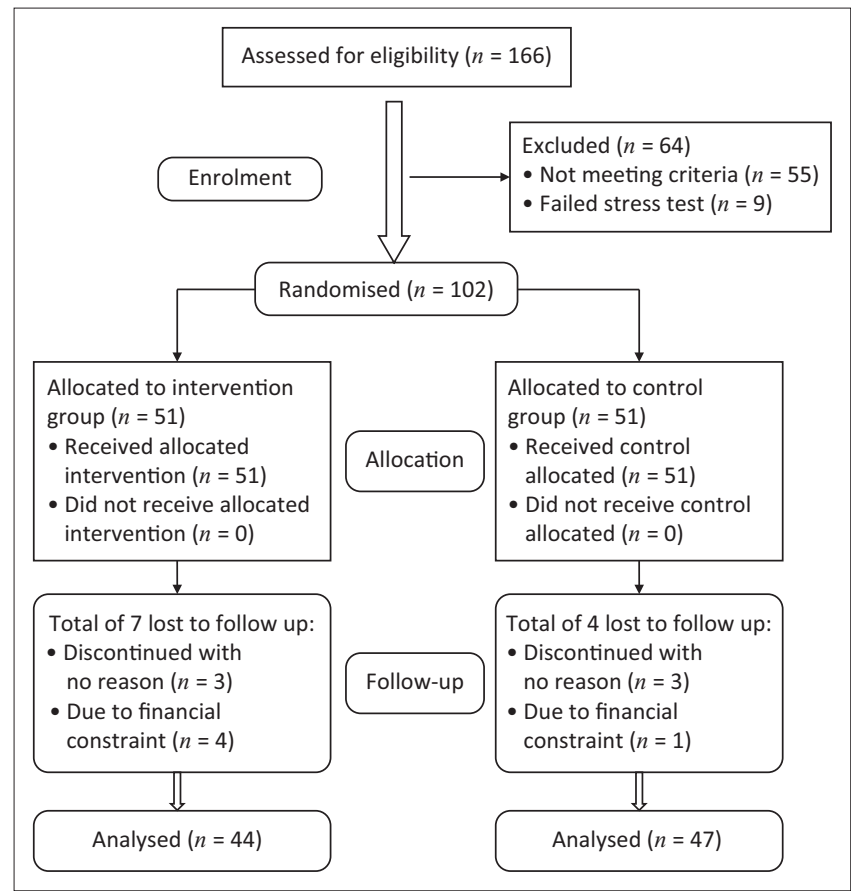

FIGURE 1: Recruitment and retention: Brief peripheral neuropathy screening tool.

visit, or 'currently absent' if the symptoms had been there but were not present at the moment. The symptoms were graded based on the severity at that moment using the scales: 1-3, 4-6 and 7-10, which is converted into mild, moderate and severe, respectively. The symptoms assessed were as follows: muscular cramping, numbness in the feet or legs, tingling sensation, burning and aching sensations, and sharp stabbing or shooting pains. Symptoms of a sudden electric-shock-like sensation, especially during sleep, sensations in the feet whilst walking and the ability to differentiate cold from hot were also assessed. ${ }^{25}$

The Brief Peripheral Neuropathy Screening (BPNS) tool confirmed the presence of neuropathy, which is a validated and reliable tool used as both an objective and subjective method for the diagnosis of neuropathy, especially DSPN, amongst HIV-positive individuals. ${ }^{26}$ It can be administered by non-neurologists because of its simplicity, and it covers both signs and symptoms of neuropathy. The severity and the presence of the symptoms were scored using a scale of $1-10 ; 0=$ no symptoms, $1-3=$ mild symptoms, $4-6=$ moderate symptoms and $7-10=$ severe symptoms.

The following symptoms were assessed: burning, aching or pain; pins and needles; and numbness in feet or legs. The highest score was 6, with three points for each leg. The scores were converted into grades as follows: grade $1=$ mild neuropathy, grade 2 = moderate neuropathy and grade $3=$ severe neuropathy. A grade of $\geq 1$ was provided when symptoms were present in both legs. The sense of vibration and the quality of the Achilles tendon reflex (TA) were the objective signs tested in the BPNS. The sense of vibration was evaluated using a $128-\mathrm{Hz}$ tuning fork struck maximally and applied to the great toe at the distal interphalangeal joints bilaterally. Sense of vibration was scored as normal if the vibration was felt for $>10 \mathrm{~s}$, mild loss if felt for $6 \mathrm{~s}-10 \mathrm{~s}$, moderate loss if felt for $<5 \mathrm{~s}$ and severe loss if no vibration was felt. The reflexes of TA were assessed with the participant seated on a chair. The examiner then dorsiflexed the foot to $90^{\circ}$ and struck the TA using a reflex hammer. The TA reflex was felt in the hand of the examiner as a contraction of the gastrocnemius muscle. The participant was then instructed to clench his or her fist, and the reflexes were graded as follows: $1=$ hypoactive, $2=$ normal, $3=$ hyperactive, $4=$ clonus and $0=$ non-reactive.

\section{Study measures \\ Balance and gait assessment}

The Tinetti Performance-Oriented Mobility Assessment (POMA) scale was used to evaluate the performance of the balance and gait of the subjects. It can be simply implemented using a hard armless chair. The POMA consists of two subscales: a balance subscale (POMA-B) and a gait subscale (POMA-G). The POMA-B evaluated the following items: $1=$ sitting balance that is safe and steady, $0=$ when lean or slide, 2 = rise, 3 = attempt to rise, $4=$ immediate standing balance (first $5 \mathrm{~s}$ ), 5 = ability to stand in one attempt, $6=$ nudged (participant assumed a position with the feet as close as possible and the examiner pushed the participant slightly at the sternum with the palm of the hand three times), 7 = same position as item six but with both eyes closed, $8=$ turning (participant turned $360^{\circ}$ ) and $9=$ back to sitting position. Some items were scored as binary $(0=$ inability to perform, $1=$ ability to perform), whilst others were scored as follows: $0=$ inability, 1 = adaptive and $2=$ normal. The POMA-B has a total of 16 marks; $<10=$ poor balance ability, $10-13=$ good balance ability and 14-16 = excellent balance ability.

The POMA-G evaluated the following items: $1=$ initiation of gait (immediately after given the command, 'GO'), 2 = same step length and height bilaterally, $3=$ step symmetry, $4=$ step continuity, 5 = path deviation, $6=$ stability of the trunk and $7=$ walking stance phase. Some items were scored as binary ( 0 = inability to perform, $1=$ ability to perform $)$, whilst others were scored as $0=$ inability, $1=$ adaptive and $2=$ normal. Participants were allowed a rest period between items if needed. The POMA-G has a total of 12 marks: a score of $<9$ indicates poor gait ability, 9-10 indicates good gait ability and 11-12 indicates excellent gait ability. ${ }^{27}$

\section{Procedure}

\section{Progressive resistance exercise group}

A 12-week programme of progressive resistance excercise (PRE) was adopted from the American College of Sports Medicine guidelines for PLHIV. ${ }^{28}$ The exercise intervention was administered by senior physiotherapists specialised in exercise and sports sciences. The exercise session included light stretching of the quadriceps, gluteal muscles, hamstrings, tibialis anterior and calf muscles for $5 \mathrm{~min}$ to warm up. The proper training included strengthening of each of the following groups of muscles: quadriceps, gluteal, hamstrings, tibialis anterior and calf muscles. The participants performed 
strengthening exercises using the quadriceps bench (Enraf Nonius, Holland) with initial intensity set at 55\% of one repetition maximum (1RM). The resistance level for each machine was gradually increased to $65 \%$ of $1 R M$ to maintain the PRE effect. At the initial stage, each group of muscles performed two sets of 10 repetitions, with a resting period of $3 s-5 s$ in between repetitions and a 5-min resting period in between the sets during the first 2 weeks. The set of 10 repetitions was increased to three for each muscle group during the remaining 10 weeks (weeks 3-12). The session ended with walking for 5 min to cool down. The exercise was conducted three times per week for three months. Vital signs were carefully monitored throughout the duration of the exercises. Borg rating of perceived exertion (RPE) is an outcome measure scale used to monitor progress and mode of exercise in individuals undergoing rehabilitation. The exertional rate was assessed using the Borg scale during the exercise training and immediately after the training period. ${ }^{29}$ Study outcomes were measured at baseline, 6 weeks and 12 weeks. All subjects continued on their ART drugs and to receive routine healthcare including ART drugs and medical consultation throughout the study.

\section{Control group}

The participants in this group were asked not to undertake any training or research involving exercise training for the period of the study. However, they also continued receiving routine healthcare including ART drugs and medical consultations.

\section{Statistical analysis}

Statistical analyses were performed using IBM Statistical Package for Social Sciences (SPSS) (version 23.0, SPSS Inc., Chicago IL, United States), with normality being assessed using the Shapiro-Wilk Test and graphical methods. Normality of data distribution were not achieved; thus, the analyses were conducted using non-parametric statistics with the Mann-Whitney $U$ test (for between groups) and the Friedman test (for baseline, 6-week and 12-week differences). The basic statistics were represented with median and interquartile ranges (IQR). An alpha level of $<0.05$ was used to indicate significance.

\section{Results}

The age range of the participants was $20-55$ years. The mean ( \pm standard deviation [ \pm s.d.]) age of the experimental and CG were $35.98( \pm 8.53)$ and $36.13( \pm 8.10)$ years, respectively. The socio-demographic and basic health status characteristics of the participants were similar in all baseline measures between the groups (Table $1 \mathrm{a}$ and $1 \mathrm{~b})$. Seven $(6.9 \%)$ of the 51 participants randomised to the PRE group dropped out, whilst four (3.9\%) of the 51 randomised to the CG dropped out (Figure 1). Exercise subjects who did not drop out had excellent adherence attending $95 \%$ of scheduled exercise sessions.

Significant differences were observed for balance measures across the PRE group ( $p<0.05$; Table 2 ). Post-hoc analysis of Wilcoxon signed-rank test showed significant improvement from the baseline to 6 weeks of intervention (effect size $r=0.88, p=0.001$ ), from baseline to 12 weeks post-intervention (effect size $0.88, p=0.001$ ) and from 6 weeks to 12 weeks postintervention (effect size $r=0.86, p=0.001$ ). In contrast, the CG experienced no significant improvement $(p>0.05)$.

Also, significant improvements for gait ability measures were observed across the PRE group (Table 2). Post-hoc analysis of Wilcoxon signed-rank test indicated significant improvement from baseline to 6 weeks (effect size $r=0.56$, $p=0.001$ ), from baseline to 12 weeks (effect size $=0.87$, $p=0.001$ ) and from 6 weeks to 12 weeks (effect size $r=0.79, p=0.001)$. No positive changes in gait measures were observed over time in the CG $(p<0.05)$.

At 6 and 12 weeks of the intervention, statistically significant differences were observed between the experimental and the CG in balance measures with effect size $r=0.71, p=0.001$ and effect size $r=0.85, p=0.001$ respectively; and for gait measures with effect size $r=0.29, p=0.006$ and effect size $r=$ $0.63, p=0.001$ (Table 3).

\section{Discussion}

This study was conducted to evaluate the effect of strength training on balance impairment and gait disturbance in individuals affected with HIV-related neuropathy. The exercise intervention improved balance impairment and gait disturbance in people living with HIV-related DSPN on ART who exercised for three months. The exercise group demonstrated significant improvement from six weeks for both balance impairment and walking ability.

The findings of this study prove the beneficial effect of therapeutic exercise on neuromuscular pathology causing impairment and disability, and affecting QOL. There is limited existing information on the impact of exercise on balance impairment and gait disturbance amongst HIVpositive individuals who develop neuropathy. With regard to gait disturbance, the result of the current study corroborates the work of Allet et al. ${ }^{30}$ who used 12 weeks of exercise to improve the gait performance of persons with diabetes. Significant favourable changes were observed in the gait performance of participants following a supervised strength exercise programme. In contrast, Kruse et al. ${ }^{31}$ found no positive changes in balance or strength in patients with diabetic neuropathy following supervised PRE for $60 \mathrm{~min}$, twice a week for 12 weeks. They concluded that it could be because the treatment administered was not intense enough to produce a positive effect on balance and muscular strength. However, Graham et al. ${ }^{32}$ observed significant improvement

TABLE 1a: Socio-demographic status of the respondents.

\begin{tabular}{|c|c|c|c|c|c|c|c|c|}
\hline \multirow[t]{2}{*}{ Characteristics } & \multicolumn{2}{|c|}{$\begin{array}{l}\text { All participants } \\
(N=91)\end{array}$} & \multicolumn{2}{|c|}{ PRE $(N=44)$} & \multicolumn{2}{|c|}{ CG $(N=47)$} & \multirow[t]{2}{*}{$t$} & \multirow[t]{2}{*}{$p$} \\
\hline & Mean & s.d. & Mean & s.d. & Mean & s.d. & & \\
\hline Age (years) & 36.05 & 8.03 & 35.98 & 8.53 & 36.13 & 8.10 & 1.114 & 0.331 \\
\hline Weight (kg) & 68.42 & 16.39 & 70.96 & 15.81 & 70.20 & 16.21 & 2.437 & 0.091 \\
\hline Height $(m)$ & 1.67 & 0.11 & 1.67 & 0.11 & 1.67 & 0.12 & 0.042 & 0.959 \\
\hline
\end{tabular}

PRE, progressive resisted exercise; CG, control group; s.d., standard deviation. 
TABLE 1b: Socio-demographic status of the respondents.

\begin{tabular}{|c|c|c|c|c|c|c|}
\hline \multirow[t]{2}{*}{ All participants $(N=91)$} & \multicolumn{2}{|c|}{$\operatorname{PRE}(N=44)$} & \multicolumn{2}{|c|}{ CG $(N=47)$} & \multirow[t]{2}{*}{$U$} & \multirow[t]{2}{*}{$p$} \\
\hline & $N$ & $\%$ & $N$ & $\%$ & & \\
\hline \multicolumn{7}{|l|}{ Gender } \\
\hline Male & 20 & 45.5 & 18 & 38.3 & 0.51 & 0.773 \\
\hline Female & 24 & 54.5 & 29 & 61.7 & - & - \\
\hline \multicolumn{7}{|l|}{ How infected } \\
\hline Having sex with men & 16 & 36.4 & 25 & 53.2 & 0.701 & 0.522 \\
\hline Injecting drugs & 7 & 15.9 & 1 & 2.1 & & \\
\hline Exposure to blood products & 2 & 4.5 & 5 & 10.6 & $\cdot$ & \\
\hline \multicolumn{7}{|l|}{ Level of education } \\
\hline No formal education & 4 & 9.1 & 25 & 53.2 & 1.603 & 0.449 \\
\hline Primary school & 4 & 9.1 & 16 & 34.0 & $\cdot$ & $\cdot$ \\
\hline Secondary school & 24 & 54.5 & 1 & 2.1 & $\cdot$ & $\cdot$ \\
\hline \multicolumn{7}{|l|}{ Health status } \\
\hline Very poor & 16 & 36.4 & 11 & 23.4 & 1.012 & 0.603 \\
\hline Poor & 24 & 54.5 & 33 & 70.2 & & \\
\hline Neither poor nor good & 4 & 9.1 & 3 & 6.4 & & \\
\hline Good & 0 & 0.0 & 0 & 0.0 & - & - \\
\hline \multicolumn{7}{|l|}{ Marital status } \\
\hline Single & 12 & 27.3 & 8 & 17.1 & 1.856 & 0.10 \\
\hline Married & 14 & 31.8 & 19 & 40.4 & $\cdot$ & - \\
\hline Widow or widower & 8 & 18.2 & 11 & 23.4 & - & - \\
\hline Divorced/separated & 10 & 22.7 & 9 & 19.1 & $\cdot$ & - \\
\hline \multicolumn{7}{|l|}{ Duration since AIDS diagnosis } \\
\hline$\leq 3$ years ago. & 6 & 13.6 & 7 & 14.9 & $\cdot$ & 0.64 \\
\hline $4-6$ years ago & 10 & 22.7 & 13 & 27.7 & $\cdot$ & - \\
\hline$\leq 3$ years ago. & 10 & 22.7 & 8 & 17.1 & 0.875 & 0.96 \\
\hline $4-6$ years ago & 27 & 61.4 & 30 & 63.8 & $\cdot$ & $\cdot$ \\
\hline$\geq 7$ years ago & 7 & 15.9 & 9 & 19.1 & $\cdot$ & - \\
\hline \multicolumn{7}{|c|}{ ARV regimen combination started with } \\
\hline Not on D4T & 24 & 54.5 & 28 & 59.6 & 1.702 & 0.87 \\
\hline On D4T & 20 & 45.5 & 19 & 40.4 & $\cdot$ & - \\
\hline \multicolumn{7}{|c|}{ Current ARV regimens' combination } \\
\hline Non-4T including & 37 & 84.1 & 39 & 83.0 & 1.547 & 0.77 \\
\hline D4T including & 7 & 15.9 & 8 & 17.0 & - & - \\
\hline \multicolumn{7}{|c|}{ ARV regimen changes since started } \\
\hline No changes & 10 & 22.7 & 13 & 27.7 & 0.7743 & 0.12 \\
\hline Once or more changes & 34 & 7.3 & 34 & 72.3 & & \\
\hline \multicolumn{7}{|c|}{ The onset of DSPN symptoms and signs } \\
\hline Before starting on ARVs & 5 & 11.4 & 9 & 19.1 & 0.321 & 0.082 \\
\hline After starting on ARVs & 39 & 88.6 & 38 & 80.9 & $\cdot$ & - \\
\hline \multicolumn{7}{|c|}{ After how long on ARVs when DSPN started } \\
\hline Within the first 12 months & 20 & 45.5 & 19 & 40.4 & 0.567 & 0.69 \\
\hline After the first 12 months & 24 & 54.5 & 28 & 59.6 & & \\
\hline
\end{tabular}

Average CD4 (cells/mm2): PRE Median = 11, PRE IQR =1.0; CG Median = 10, CG IQR = 3.0; $U=11.022 ; p=0.00$.

$\mathrm{U}$, Mann Whitney Test; $t, T$-test; ARV, antiretroviral; D4T, stavudine; DSPN, Distal symmetrical polyneuropathy; PRE, progressive resistance exercise; CG, control group ; IQR, interquartile range.

TABLE 2: Differences within groups in balance and gait scores across baseline, 6 weeks and 12 weeks.

\begin{tabular}{|c|c|c|c|c|c|c|c|c|c|c|}
\hline \multirow[t]{2}{*}{ Variables } & \multirow[t]{2}{*}{ Study groups } & \multirow[t]{2}{*}{$N$} & \multicolumn{2}{|c|}{ Baseline } & \multicolumn{2}{|c|}{6 weeks } & \multicolumn{2}{|c|}{12 weeks } & \multirow[t]{2}{*}{$X^{2}$} & \multirow[t]{2}{*}{$\bar{p}$} \\
\hline & & & Median & IQR & Median & IQR & Median & IQR & & \\
\hline \multirow[t]{2}{*}{ Balance } & PRE & 44 & 10.0 & $8.00-12.00$ & 12.0 & $9.20-13.30$ & 15.00 & $13.6-18.30$ & 87.034 & $<0.001^{*}$ \\
\hline & CG & 47 & 10.0 & $7.10-11.80$ & 9.00 & $7.00-11.00$ & 9.00 & $7.08-10.60$ & 11.333 & 0.513 \\
\hline \multirow[t]{2}{*}{ Walking gait } & PRE & 44 & 7.00 & $5.60-9.10$ & 8.00 & $6.20-10.50$ & 11.00 & $10.0-13.70$ & 67.304 & $<0.001^{*}$ \\
\hline & CG & 47 & 8.00 & $6.30-10.70$ & 8.00 & $6.30-11.00$ & 8.00 & $6.50-10.90$ & 8.797 & 0.12 \\
\hline
\end{tabular}

PRE, progressive resistance exercise; $C G$, control group; IQR, interquartile range; $X^{2}$, Chi square of Wilcoxon signed-rank test.

*, Significant at $p<0.05$ 
TABLE 3: Between-groups comparison of the outcomes at baseline, 6 weeks and 12 weeks.

\begin{tabular}{|c|c|c|c|c|c|c|c|}
\hline \multirow[t]{2}{*}{ Variable } & \multirow[t]{2}{*}{ Time period } & \multicolumn{2}{|c|}{ PRE $(n=44)$} & \multicolumn{2}{|c|}{ CG $(n=47)$} & \multirow[t]{2}{*}{$U$} & \multirow[t]{2}{*}{$p$} \\
\hline & & Median & IQR & Median & IQR & & \\
\hline \multirow[t]{3}{*}{ Balance } & Baseline & 10.0 & $8.20-12.00$ & 10.0 & $7.80-12.10$ & 1016.000 & 0.677 \\
\hline & 6 weeks & 12.0 & $9.20-14.00$ & 9.00 & $8.00-11.00$ & 193.500 & $<0.001^{*}$ \\
\hline & 12 weeks & 15.0 & $12.10-17.00$ & 9.00 & $7.80-11.60$ & 19.000 & $<0.001^{*}$ \\
\hline \multirow[t]{3}{*}{ Walking (gait) } & Baseline & 7.00 & 5.30-9.00 & 8.00 & $6.20-9.00$ & 696.000 & 0.578 \\
\hline & 6 weeks & 9.00 & $7.40-11.30$ & 8.00 & $6.40-9.00$ & 965.000 & $0.006^{*}$ \\
\hline & 12 weeks & 10.0 & $7.30-13.00$ & 8.00 & $7.00-9.60$ & 290.000 & $<0.001 *$ \\
\hline
\end{tabular}

$\mathrm{U}$, Mann-Whitney Test; IQR, interquartile range; PRE, progressive resistance exercise; CG, control group.

*, Significant at $p<0.05$

in balance impairment in patients with non-HIV associated neuropathy after 12 weeks of unsupervised, communitybased strengthening exercise, agreeing with the positive change noted in balance and walking ability following PRE in the current study. Richardson, Sandman and Velas ${ }^{33}$ subjected patients with diabetic PN to PRE for three weeks every day for $35 \mathrm{~min}-50 \mathrm{~min}$ per session using $60 \%-70 \%$ of $1 \mathrm{RM}$. Significant improvement was observed in clinical measures of postural performance $(p<0.05)$, which corroborates the finding of this study.

It has been stated that the strengthening of groups of muscles around the knee joint is related to positive changes in stride length and cadence during walking and can influence balance performance, in general. It is an intervention that can also improve walking ability. ${ }^{34}$ Judge, Underwood and Gennosa ${ }^{35}$ found that in older individuals with PN (mean age 82.1 years), 12 weeks of resistance exercises three times per week produced a significant modulating effect on strength, balance parameters and gait velocity when compared with a CG that performed only flexibility exercises $(p<0.05)$, tallying with results from the current study. These results accord with the postulated literature that states that resistance exercises can attenuate motor deficits caused by PN, thus improving inter- and intramuscular coordination as well as neural control, and leading to improvement in balance impairment and gait disturbance. ${ }^{36}$

\section{Conclusion}

This research study provided insights into the use of moderate-intensity strength exercises and the use of progressive resistance. The clinical implication is that PRE may be of use to physiotherapists when managing individuals with HIV-related DSPN for whom exercises are not contraindicated. This study supports the safety of moderateintensity PRE and the improvement of impaired balance and walking disturbance in PLHIV-related DSPN. The use of PRE could minimise residual disabilities from HIV-related DSPN. This research study may serve as a starting point for further studies of larger sample size and longer duration.

\section{Limitations}

Lack of diagnostic tools such as electromyogram (EMG) or nerve conducting study to confirm the presence of neuropathy was one of the study's limitations, as the study was conducted in a poor resource environment. The authors included both participants with symptoms before starting antiretrovirals
(ARVs) and whilst starting ARVs. However, the tools used in this study were validated and reliable for the diagnosis of HIVrelated DSPN. Also, participants assigned to the intervention group could not be blinded to the type of interventions, and the generalisability of the results is limited because of the use of a non-probability sampling technique. Furthermore, information was not available on follow-up post-intervention to assess any long-term changes in the functional status.

\section{Acknowledgements}

The researchers appreciate the assistance of physiotherapists and administrative staff of the various hospitals with their assistance with this study.

\section{Competing interests}

The authors declare that they have no financial or personal relationships that may have inappropriately influenced them in writing this article.

\section{Authors' contributions}

A.M.Y. and M.S.D. participated in the study conception, design, acquisition and analysis of the data. S.M. participated in drafting the manuscript, interpretation of the data, critical revision for publication and approval for submission.

\section{Ethical considerations}

This study was approved by the Biomedical Research Ethics Committee of the University of KwaZulu-Natal (South Africa) (ethics number: BFC413/15) and by the Human Research Ethics Committee of Kano state Hospitals Management Board (HMB/GEN/488/VOL.I), Nigeria. The study has been registered with the Pan African Clinical Trial Registry (www.pactr.org) with the following registration number: PACTR201707002173240. A written and signed informed consent was obtained from all recruited participants for the study by a third party who is independent and not part of the core study team; the consent form was designed by the Biomedical Research Ethics Committee of University of KwaZulu-Natal (BREC) according to the WMA Helsinki Declaration and good clinical practice (GCP).

\section{Funding information}

The authors received no financial support for the research, authorship or publication of this article. 


\section{Data availability}

The data are not publicly available because of restrictions as it contains information that could compromise the privacy of research participants. Relevant files of this work will be shared on request from the corresponding author.

\section{Disclaimer}

The views and opinions expressed in this article are those of the authors and do not necessarily reflect the official policy or position of any affiliated agency of the authors.

\section{References}

1. Martyn CN, Hughes RAC. Epidemiology of peripheral neuropathy. J Neurol Neurosurg Psychiatry. 1997;62(4):310-318. https://doi.org/10.1136/jnnp.62.4.310

2. Chen $H$, Clifford DB, Deng L, et al. Peripheral neuropathy in ART-experienced patients: Prevalence and risk factors. J Neurovirol. 2013;19(6):557-564. https:// doi.org/10.1007/s13365-013-0216-4

3. Margolis AM, Heverling H, Pham PA, Stolbach A. A review of the toxicity of HIV medications. J Med Toxicol. 2014;10(1):26-39. https://doi.org/10.1007/s13181013-0325-8

4. Ngassa Mbenda HG, Wadley A, Lombard Z, Cherry C, Price P, Kamerman P. Genetics of HIV-associated sensory neuropathy and related pain in Africans. Genetics of HIV-associated sensory neuropathy and related pain in Africans.
Neurovirol. 2017;23(4):511-519. https://doi.org/10.1007/s13365-017-0532-1

5. Lifson AR, Workneh S, Shenie T, et al. Prevalence and factors associated with use of khat: A survey of patients entering HIV treatment programs in Ethiopia. Addict Sci Clin Pract. 2017;12(1):3. https://doi.org/10.1186/s13722-016-0069-2

6. Saylor D, Nakigozi G, Nakasujja N, et al. Peripheral neuropathy in HIV-infected and uninfected patients in Rakai, Uganda. Neurology. 2017;89(5):485-491. https:// doi.org/10.1212/WNL.0000000000004136

7. Prior DE, Song $\mathrm{N}$, Cohen JA. Neuromuscular diseases associated with human immunodeficiency virus infection. J Neurol Sci. 2018;387:27-36. https://doi. org/10.1016/j.jns.2018.01.016

8. Mkandla K, Myezwa H, Musenge $E$. The effects of progressive-resisted exercises on muscle strength and health-related quality of life in persons with HIV-related poly-neuropathy in Zimbabwe. AIDS Care [serial online]. 2016 [cited $2016 \mathrm{Ju}$ 18];28(5):639-643. Available from: http://www.ncbi.nlm.nih.gov/pubmed/ 26729347

9. Ownby KK, Dune LS. The processes by which persons with HIV-related periphera neuropathy manage their symptoms: A qualitative study. J Pain Symptom Manage. 2007;34(1):48-59. https://doi.org/10.1016/j.jpainsymman.2006.10.013

10. Joska JA, Westgarth-Taylor J, Hoare J, et al. Neuropsychological outcomes in adults commencing highly active anti-retroviral treatment in South Africa: A prospective study. BMC Infect Dis. 2012;12(1):1-8. https://doi.org/10.1186/1471-2334-12-39

11. Erlandson $\mathrm{K}$, Plankey $\mathrm{M}$, Springer $\mathrm{G}$, et al. Fall frequency and associated factors among men and women with or at risk for HIV infection. HIV Med. 2016;17(10):740-748. https://doi.org/10.1111/hiv.12378

12. Kars HJJC, Hijmans JM, Geertzen JHB, Zijlstra W. The effect of reduced somatosensation on standing balance: A systematic review. J diabetes Sci Technol. 2009;3(4):931-943. https://doi.org/10.1177/193229680900300441

13. Verma S, Estanislao L, Simpson D. HIV-associated neuropathic pain. CNS Drugs. 2005;19(4):325-334. https://doi.org/10.2165/00023210-200519040-00005

14. Breitbart W, Dibiase L. Current perspectives on pain in AIDS. Oncology [serial online]. 2002 [cited 2017 Apr 20];16(6):818-829, 834-835. Available from: http:// europepmc.org/abstract/med/12164562

15. Pandya R, Krentz HB, Gill MJ, Power C. HIV-related neurological syndromes reduce health-related quality of life. Can J Neurol Sci. 2005;32(2):201-204. https://doi. org/10.1017/S0317167100003978

16. Hand GA, Lyerly GW, Jaggers JR, Dudgeon WD. Impact of aerobic and resistance exercise on the health of HIV-infected persons. Am J Lifestyle Med. 2009;3(6): 489-499. https://doi.org/10.1177/1559827609342198
17. Mutimura E, Stewart A, Crowther NJ, Yarasheski KE, Cade WT. The effects of exercise training on quality of life in HAART-treated HIV-positive Rwandan subjects with body fat redistribution. Qual Life Res. 2008;17(3):377-385. https://doi. with body fat redistribution. Q
org/10.1007/s11136-008-9319-4

18. O'Brien K, Nixon S, Tynan AM, Glazier R. Aerobic exercise interventions for adults living with HIV/AIDS. Cochrane Database Syst Rev [serial online]. 2010 Aug 4 [cited 2021 Aug 4];2010(8):CD001796. Available from: https://pubmed.ncbi.nlm.nih. gov/20687068/

19. Fillipas S, Cherry CL, Cicuttini F, Smirneos L, Holland AE. The effects of exercise training on metabolic and morphological outcomes for people living with HIV: A systematic review of randomised controlled trials. HIV Clin Trials. 2010;11(5): 270-282. https://doi.org/10.1310/hct1105-270

20. O'Brien KK, Tynan A-M, Nixon SA, Glazier RH. Effectiveness of progressive resistive exercise (PRE) in the context of HIV: Systematic review and meta-analysis using the Cochrane collaboration protocol. BMC Infect Dis. 2017;17(1):268. https://doi. org/10.1186/s12879-017-2342-8

21. Richard W. Resistance training: Exercises, benefits \& amp: Definition [homepage on the Internet]. 2016 [cited 2017 Apr 20]; p. 1-4. Available from: http://www. emedicinehealth.com/strength_training/article_em.htm

22. Veeravelli S, Najafi B, Marin I, Blumenkron F, Smith S, Klotz SA. Exergaming in older people living with HIV improves balance, mobility and ameliorates some aspects of frailty. J Vis Exp. 2016;116:e54275. https://doi.org/10.3791/54275

23. Pullen SD, Chigbo NN, Nwigwe EC, Chukwuka CJ, Amah CC, Idu SC. Physiotherapy intervention as a complementary treatment for people living with HIV/AIDS. HIV/ AIDS Res Palliat Care. 2014;6:99-107. https://doi.org/10.2147/HIV.S62121

24. Maharaj SS, Yakasai AM. Does a rehabilitation program of aerobic and progressive resisted exercises influence HIV-induced distal neuropathic pain?
Am J Phys Med Rehabil. 2018;97(5):364-369. https://doi.org/10.1097/ Am J Phys Med Rehabil.

25. Venkataramana AB, Skolasky RL, Creighton JA MJ, Venkataramana AB, Skolasky RL, Creighton JA, McArthur JC. Diagnostic utility of the subjective peripheral neuropathy screen in HIV-infected persons with peripheral sensory polyneuropathy. neuropathy screen in HIV-infected persons with peripheral sensory polyneuropathy. http://go.galegroup.com/ps/i.do?p=AONE\&sw=w\&issn=10530894\&v=2.1\&it=r\&id http://go.galegroup.com/ps/i.do?p=AONE\&sw=w\&issn=1053089
=GALE\%7CA135456949\&sid=googleScholar\&linkaccess=fulltext

26. Cherry CLC, Wesselingh SLS, Lal L, McArthur JJC. Evaluation of a clinical screening tool for HIV-associated sensory neuropathies. Neurology. 2005;65(11): 1778-1781. https://doi.org/10.1212/01.wnl.0000187119.33075.41

27. Faber MJ, Bosscher RJ, Van Wieringen PCW. Clinimetric properties of the performance-oriented mobility assessment. Phys Ther. 2006;86(7):944-954. https://doi.org/10.1093/ptj/86.7.944

28. Thompson PD, Arena R, Riebe D, Pescatello LS. Invited commentary ACSM's new preparticipation health screening recommendations from ACSM's guidelines for exercise testing and prescription, ninth edition. Curr Sport Med. 2013;12(4): 215-217. https://doi.org/10.1249/JSR.0b013e31829a68cf

29. Borg GAV. Psychophysical bases of perceived exertion. Plast Reconstr Surg 1954;14(5):377-381. https://doi.org/10.1249/00005768-198205000-00012

30. Allet $L$, Armand $S$, Aminian $K$, et al. An exercise intervention to improve diabetic patients' gait in a real-life environment. Gait Posture. 2010;32(2):185-190. https://doi.org/10.1016/j.gaitpost.2010.04.013

31. Kruse RL, LeMaster JW, Madsen RW. Fall and balance outcomes after an intervention to promote leg strength, balance, and walking in people with diabetic peripheral neuropathy: 'Feet first' randomized controlled trial. Phys Ther 2010;90(11):1568-1579. https://doi.org/10.2522/ptj.20090362

32. Graham RC, Hughes RAC, White CM. A prospective study of physiotherapist prescribed community based exercise in inflammatory peripheral neuropathy. $J$ prescribed community based exercise in inflammatory peripheral neuropathy.
Neurol. 2007;254(2):228-235. https://doi.org/10.1007/s00415-006-0335-4

33. Richardson JJK, Sandman D, Vela SA, et al. A focused exercise regimen improves clinical measures of balance in patients with peripheral neuropathy. Arch Phys Med Rehabil [serial online]. 2001 Feb [cited 2016 Aug 15];82(2):205-209. Med Rehabil [serial online]. 2001 Feb [cited 2016 Aug 15]
Available from: http://www.ncbi.nlm.nih.gov/pubmed/11239311

34. Persch LN, Ugrinowitsch C, Pereira G, Rodacki ALF. Strength training improves fallrelated gait kinematics in the elderly: A randomized controlled trial. Clin Biomech. 2009;24(10):819-825. https://doi.org/10.1016/j.clinbiomech.2009.07.012

35. Judge JO, Underwood M, Gennosa T. Exercise to improve gait velocity in older persons. Arch Phys Med Rehabil [serial online]. 1993 Apr [cited 2017 Jul 3];74(4):400-406. Available from: http://www.ncbi.nlm.nih.gov/pubmed/8466422

36. Granacher U, Gollhofer A, Strass D. Training induced adaptations in characteristics of postural reflexes in elderly men. Gait Posture. 2006;24(4):459-466. https://doi. org/10.1016/j.gaitpost.2005.12.007 